\title{
An Intercultural Analysis of Meta-discourse Markers as Persuasive Power in Chinese and American Political Speeches
}

\author{
Hongyu Mai \\ College of Foreign Languages, Guangxi University, Nanning, China
}

Email address:

maihongyu@gxu.edu.cn

To cite this article:

Hongyu Mai. An Intercultural Analysis of Meta-discourse Markers as Persuasive Power in Chinese and American Political Speeches. International Journal of Language and Linguistics. Vol. 4, No. 6, 2016, pp. 207-219. doi: 10.11648/j.ij11.20160406.13

Received: September 8, 2016; Accepted: October 10, 2016; Published: November 18, 2016

\begin{abstract}
Meta-discourse markers play a vital role in organizing the text, showing the presence of the speaker, and engaging the audience, thus they become an important aspect of persuasive power in public speeches. Based on a corpus of 60 political speeches collected from the internet, this study exams (a) how meta-discourse markers help to realize persuasive function, (b) what is the general preference in the use of meta-discourse markers in American and Chinese political speeches respectively, and (c) how cultural factors influence the choice of persuasive strategy. Quantitative analysis indicates that American speeches feature markedly more meta-discourse than Chinese speeches. Textual analysis further reveals that the difference of the two sub-corpora in the achievement of logical appeal, credible appeal, and affective appeal. These results are then discussed in terms of linguistic difference and culturally preferred rhetorical strategy.
\end{abstract}

Keywords: Meta-discourse Markers, Persuasive Power, Political Speeches

\section{Introduction}

Political speeches, which are defined as formally expressed viewpoints of national leaders, play a crucial role in expressing political opinions, influencing public opinions and building public mentality. They are supposed to be stated accurately and clearly so as to persuade the audiences into the agreement with the speaker. To achieve this purpose, different discourse strategy might be employed in different cultures.

The aim of this paper is to study how meta-discourse helps to achieve persuasiveness in political speeches, and take a contrastive approach to explore the rhetorical similarities and differences of meta-discourse as persuasive power in Chinese and American political speeches. Analyzing how persuasiveness is achieved through meta-discourse may help both American and Chinese speakers to construct better speeches, while revealing possible different rhetorical conventions favored in different cultures would provide useful cues of about how to address international audience. Besides, through this study, a better understanding about the beliefs and values shared by the Chinese society and American society may be gained.
Hyland's interpersonal model of meta-discourse is used in this thesis. According to Hyland [1], meta-discourse is the term, covering all the self-reflective expressions that are used to deal with interactional meanings in a text, and thus can assist the speaker to present his opinion as well as engage with his audiences as a member of a particular community. Firstly coined in 1959, metadiscourse has been given various definitions and classifications by different scholars [2-4]. It has been traditioally divided into textual and interpersonal discourse based on Halliday's [5] distinction between textual and interpersonal functions of language. However, Hyland [6] proposes that all meta-discourse categories are interpersonal because they all need to consider the reader in terms of knowledge, experience, and culture and so on. This new view of meta-discourse consider all discourse decisions that writer make are results of the relationship built through text between writer and reader. Hyland's interpersonal model of meta-discourse recognizes that meta-discourse consists of two kinds of interaction: interactive dimension and interactional dimension. Simply speaking, the interactive meta-discourses are used to organize propositional information, while interational meta-discourses involve 
readers in the text. The sub-categories of each meta-discourse resource are listed in Table 1.

Table 1. Hyland's interpersonal model of meta-discourse.

\begin{tabular}{ll}
\hline Interactive meta-discourse & Interactional meta-discourse \\
\hline Transitions & Hedges \\
Frame markers & Boosters \\
Endophoric markers & Attitude markers \\
Evidentials & Self mentions \\
Code glosses & Engagement markers \\
\hline
\end{tabular}

The concept of persuasion we are going to talk about here is closely related to Aritotle's three means of persuasion-logos, ethos and pathos. Logos is logical appeal, which concerns the proposition of the text. Writer or speaker makes use of whatever he has got to adjust the arrangement, length, types of evidence and so on to make his argument more convincing. Ethos, which relates to credible appeals, is realized by building a credible, confident and authoritative image. Although ethos may be related to author's reputation or celebrity, the re-establishment of his expertise in the discourse is still quite important. So towards the construction of ethos in discourse, writer or speaker should work hard to build a respectable and authoritative character. Pathos means affective appeal and is realized by involving readers into the text and promoting their affective feelings. To attain the affective appeal in a discourse, writers or speakers need to understand and consider various elements about their audiences so as to narrow the psychological distance and persuade them into his arguments.

A few researchers have combined the study of meta-discourse with that of persuasion. Crismore and Farnsworth [2] studied how meta-discourse helps to establish ethos in The Origin of Species through the calculation and analysis of code glosses, modality markers, attitude markers and commentary. Hyland [1] explored how meta-discourse helped to create rational, credible and affective appeal to realize the persuasion of the CEO's letters. In his research, we can see that the frequent use of textual meta-discourse and code glosses helps to create rational appeal; the aspects of meta-discourse which contribute to the credible appeal are hedges, emphatics, relational markers and attributors; while categories of relational markers, attitude markers, and hedges, together with the manupulation of pronoun reference helps to realize affective appeals. From both studies, we can see that the important role of meta-discourse in achieving persuasive goals. Also, we know from these researches that certain groups of meta-discourse contribute to the achievement of three means of persuasion_logos, ethos and pathos.

Meta-discourse has been investigated in different genres: textbooks [2], [7], dissertations [8-9], student essays [10], research articles [9], [11]. It has also been investigated cross-culturally between English and Finnish [12], English and Spanish [13-15] and English and Chinese [16-17] and so on.

The previous researches have revealed that the meta-discourse helps to achieve a persuasive function in different genres. It is also found that preference on the use of certain sub-category of meta-discourse differs due to the cultural differences. However, few studies have taken a more comprehensive perspective allowing for a detailed description of the persuasive effects of each category of meta-discourse and a cross-cultural comparision. Besides, earlier investigations focus on the written discourse rather than the oral discourse. There might be two reasons: First, oral discourse need to be transcribed for further analysis and this transcription involve a huge number of labors. Second, according to Halliday [5], "formal written discourses usually carry more GM and have the feature of high lexical density", which makes the study result more explicit.

Based on the previous findings and Hyland's interpersonal model of metad-iscourses, we made some adjustment and created an adapted model for the present study. (Figure 1)

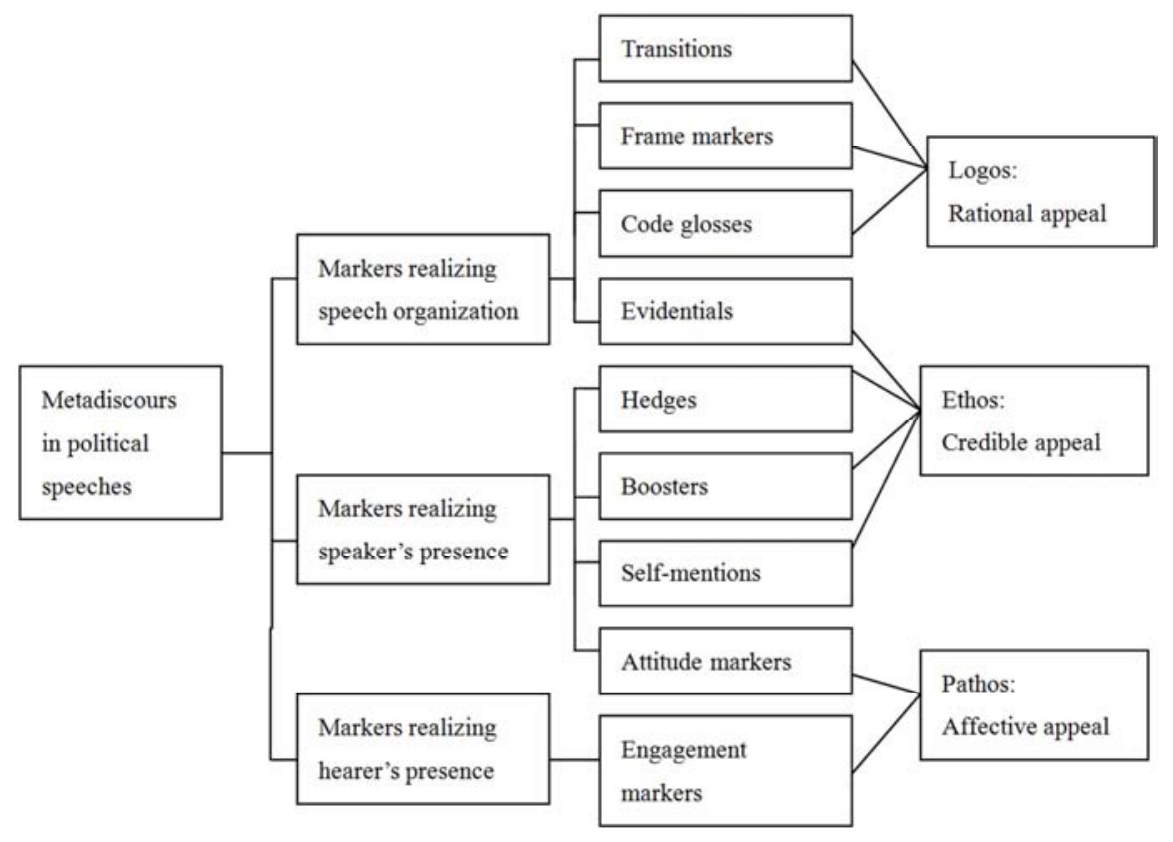

Figure 1. An adapted model of meta-discourse. 
The reasons for these modifications are listed below: First, persuasion has to be adjusted for differences in the three major components of communication: the speaker, the hearer, and the contents of the argument. Also, the three means of persuasion, logos, ethos and pathos correspond to the speeches, the speaker and the reader respectively. Hyland's model could not show the relationship clearly. Second, endophoric markers are expressions which refer to other parts of the texts. Since this category of meta-discourse can rarely be found in speeches, it is not included in our study.

This research, then, aims at providing a comprehensive cross-cultural comparison of how persuasive effects are achieved through meta-discourse markers in English and Chinese political speeches. More specifically, the research questions to be addressed in this article are:

1) How do meta-discourse markers help to realize persuasive function through means of logos, pathos and ethos in political speech respectively?

2) What is the general preference in the use of meta-discourse markers in American and Chinese political speeches?

3) How do cultural factors influence the choice of persuasive strategies?

\section{Methodology}

To address the above research questions, a contrastive approach is adopted to explore the persuasive power of meta-discourse in political speeches.

\subsection{Construction of Equivalent Sub-corpora}

Political discourse usually covers election speech, inaugural, conference debate, assembly speech and diplomatic speech and so on. To make parallel sub-corpora, we focused on conference speeches only. The selection of the speeches was based on American government official website (https://www.whitehouse.gov) and Chinese government official website (http://www.gov.cn) so as to guarantee authenticity and validity of the speech transcripts. It consisted of 30 Chinese and 30 American political speeches respectively and all the speeches were delivered from 2010 to 2015, as indicated in Table 2.

Table 2. Description of the corpus.

\begin{tabular}{lll}
\hline & American sub-corpus & Chinese sub-corpus \\
\hline No. of speeches & 30 & 30 \\
Length of texts (range) & $870-5495$ & $916-3271$ \\
Average Length of speeches & 1876 & 2264 \\
Total number of tokens & 56291 & 67913 \\
\hline
\end{tabular}

\subsection{Operationalization of Meta-discourse}

Table 3 shows us the classification and definition of the meta-discourses we are going to study. Hyland's meta-discourse model has given us clear definition of each category of meta-discourse. Meanwhile, it is still not easy to discern and qualify certain words as meta-discourse. When faced with unclear cases, the context must be taken into consideration

Table 3. Definition and classification of meta-discourses.

Meta-discourses contributing to logical appeal
Transition markers: items that make explicit pragmatic connections beween steps in an augument. This category comprises of additive, contrastive, and
consecutive markers.
Frame markers: items that signal text boundaries or elements of schematic text structure.
Code glosses: items that are used for explanation and examples. They are used to ensure that the reader or listener is able to recover writer's intended
meaning.
Meta-discourses contributing to credible appeal
Boosters: items that emphasize certainty or close dialogue. Boosters suggest that the writer or speaker recognizes potentially diverse positions but has
chosen to narrow this diversity and express their certainty in what they say.
Hedges: items that withhold commitment and open dialogue. They emphasize that the statement is based on the writer or speaker's reasoning rather than
certain knowledge.
Evidentials: items that indicate the sources of information, which guide the readers' interpretation and establish an authoritative command of the subject.
Self mentions: items that refer to the degree of explicit author presence in the text. They feature self-references and self-citations.
Meta-discourses contributing to affective appeal
Attitude markers: items that express writer or speaker's affective evaluation to proposition.
Engagement markers: items that explicitly address readers, either to focus their attention or include them as discourse participant.

\subsection{Procedure}

Both quantitative and qualitative approaches are conducted in this study.

First, a list of English and Chinese meta-discourse was developed as a coding scheme. The English one was based on the list of English meta-discourse compiled by Hyland. Since there was no existing inventory of Chinese meta-discourse, we firstly translated as many English meta-discourse markers into their Chinese equivalent and read through the corpus carefully in search of more potential meta-discourse markers.

Second, all the words in the taxomony were searched for and marked electronically in the whole corpus so that the total number of tokens of that particular feature was obtained. 
Once retrieved, each token was carefully analyzed in context to ensure that it actually functioned as a meta-discourse. Then, Ant Conc 3.2.2 was used to calculate the frequency of the each meta-discourse device in both American and Chinese sub-corpura according to the tagging. Since the total number of words of each corpus was not the same, we counted the frequency of each meta-discourse per 10,000 words, and compared each category of meta-discourses in the two sub-corpora with SPSS statistics software to see whether the significance exists (independent sample T-test, $\mathrm{t}<0.05$ ).

Finally, Aristotle's classical rhetoric was adopted to elaborate how each subcategory of meta-discourse help to achieve persuasive function through rational, credible and affective appeal. Typical examples in two sub-corpora were analyzed to give an explanatory exposition to the difference in Chinese and American politicians' usage of meta-discourse and potential roles of culture contributing to different persuasive styles.

\section{Results}

Table 4 presents descriptive statistics for the use of meta-discourse markers by the two sub-corpora under three persuasive categories. Generally speaking, meta-discourse markers are significantly more commonly present in the American sub-corpus than in Chinese sub-corpus (1151.8 vs. 572.8 per 10000 words). This implies that there is a stronger interaction between the speaker and listeners in the American political speeches than in the Chinese ones. Results also show that American speakers use the most metadisicourse markers to achieve ethos, followed by pathos and logos, while Chinese speakers use the most meta-discourse markers to achieve pathos, followed by ethos and logos.

The results will be further discussed and compared in terms of persuasive functions-logos, ethos and pathos.

Table 4. Frequency of meta-discourse markers to achieve persuasive function

\begin{tabular}{lllll}
\hline & American sub-corpus & & Chinese sub-corpus & \\
\hline & Raw number & Per 1,000 words & Raw number & Per 10,000 words \\
\hline Logos & 2454 & 435.9 & 487 & 71.7 \\
Ethos & 4030 & 715.9 & 1458 & 214.7 \\
Pathos & 3081 & 1151.8 & 2134 & 286.4 \\
Total & 9565 & 2303.6 & 4079 & 572.8 \\
\hline
\end{tabular}

\subsection{Meta-discourses Contributing to Rational Appeal}

The first factor related to the persuasiveness of a discourse is that whether the elements of arguments are connected in a reasonable way so that the readers or listeners can understand and accept the viewpoint. As for a speech, the content should be coherent and understandable. Usually, interactive discourses, showing relation between arguments, are applied by speakers to achieve this purpose. Transitions, frame markers and code glosses in this category assist to achieve the rational appeal of the commencement speeches.

Table 5. Meta-discourses contributing to rational appeal.

\begin{tabular}{|c|c|c|c|c|c|}
\hline & \multicolumn{2}{|c|}{ American sub-corpus } & \multicolumn{2}{|c|}{ Chinese sub-corpus } & \multirow[b]{2}{*}{ T-test } \\
\hline & Raw number & Per 1,000 words & Raw number & Per 10,000 words & \\
\hline Transitions & 2032 & 361.0 & 261 & 38.4 & .000 \\
\hline Frame markers & 322 & 57.2 & 146 & 21.5 & .000 \\
\hline Code glosses & 65 & 11.5 & 28 & 4.1 & .001 \\
\hline Total & 2419 & 429.7 & 435 & 64 & .001 \\
\hline
\end{tabular}

\subsubsection{Transitions}

Transitions refer to the meta-discourse markers which signal the relationship between two independent discourse. Most apparently, the use of transitions helps to make the discourse fluent and coherent. It can also help the speaker emphasize some particular parts to which he wishes that his audience can pay more attention.

Through the quantitative analysis, it is found that transition markers in American sub-corpus are almost 10 times of those in Chinese sub-corpus. (361 vs. 38.4 token per 10,000 words).

This result, to some extent, is due to the different constructional characteristics of Chinese and English. English is hypotaxis while Chinese is parataxis. In Chinese, clauses and sentences can be put together without any connectives to show their logical relationship.
American speeches usually state the logical relationship more clearly. Example (3) shows the speaker's support on the same-sex marriage. The use of because shows reason for his argument: "love is love". The first and is used to conjunct two actions which are now legal under the law. And the second and shows an additional action the speaker determinds to take in the future. Therefore, the transitions because and and here actually help to facilitate the understanding of this discourse and achieve rational appeal by signaling the logical relationship of linguistic units.

Example (4) is a typical Chinese sentence in public speaking. Though the parallel and additive relationship exists among linguistic units “从大处着眼 (focus on the larger picture)”, “把握构建新型大国关系总目标 (focus on the overall goal of building a new model of major-country relationship)” and “认清两国共同利益远远大于分歧(both countries fully recognize that our shared interests far 
outweigh our differences)". The relationship is not shown in any connectives directly. Chinese speeches comprise less connective to state the logical relationship between linguistic units.

(3) Because "love is love," today-50 years later - two men or two women can walk into the courthouse in that same city of Wilmington and get a marriage license. And we won't rest until that freedom to marry is available to any loving, committed couple in this country.

(4) 我们双方应该坚持从大处着眼, 把握构建新型大国 关系总目标，认清两国共同利益远远大于分歧；应该相互 尊重、平等相待, 尊重彼此主权和领土完整, 尊重彼此对 发展道路的选择, 不把自己的意志和模式强加于对方; 应 该善于管控矛盾和摩擦，坚持通过对话协商、以建设性方 式增进理解、扩大共识。

(What is important is that both countries focus on the larger picture and the overall goal of building a new model of major-country relationship, and fully recognize that our shared interests far outweigh our differences. Our two countries need to respect other and treat each other as equals, respect each other's sovereignty and territorial integrity as well as choices for development paths, and refrain from attempting to impose one's will or model on the other side.)

As for the use of different sub-categories of transitions (i.e. additive, contrastive and consecutive), there is no significant difference in the two sub-corpora. Pilar Mur-Dueñas [15] found that English texts present a higher frequency of contrastive and consecutive logical markers and a lower use of additive logical markers than the Spanish texts, which was explained as a retrogressive argumentative style in the English argumentation and a progressive style in the Spanish comparable texts. There is no such a difference between the American and Chinese speeches.

\subsubsection{Frame Markers}

Frame markers are used to organize the text and signal text boundaries so that it is clear what arguments are discussed and will be discussed. Frame markers includes topicalister (I argue here, my purpose is, well, right, now, OK) and sequencers (first, second, next, finally).

Topicalisers refer to linguistic elements that label, predict and shift argument, providing framing information of the discourse and making the arguments clear to listeners. For example, the topilicalisers in example (5) and example (6) helps to arouse the audience's attention toward the upcoming topics.

(5) Now, North Korea is calling for dialogue.

(6) 在此, 我谨对研讨会的成功举行表示热烈祝贺, 向 参加本次研讨会的两国各界人士和涉农部门人士, 表示诚 挚的欢迎和由衷的敬意。

(While extending my warm congratulations to the successful opening of this symposium, I wish to express cordial welcome and deep respect to all the Chinese and Americans present today, particularly those who have been working in agriculture-related areas.)

Sequencers refer to the elements which connect parts of the discourse in a linear, progresssive manner so as to facilitate the readers' decoding process. Sequencers signal the outline of the text and guide the listeners in an orderly way and explain the speakers' viewpoint step by step.

(7) And here's what you need to know. First, I will not sign a plan that adds one dime to our deficits- [...] Second, we 've estimated that most of this plan can be paid for by finding savings within the existing health care system, $[. .$.

(8) 推动文明交流互鉴, 需要秉持正确的态度和原则。 我认为, 最重要的是坚持以下几点。

第一，文明是多彩的，人类文明因多样才有交流互鉴的 价值。[...... 第二, 文明是平等的, 人类文明因平等才有 交流互鉴的前提。 [...... 第三，文明是包容的，人类文明 因包容才有交流互鉴的动力。 $[\ldots . . .$.

(To promote exchanges and mutual learning among civilizations, we must adopt a right approach with some important principles. They, in my view, contain the following: First, civilizations have come in different colors, and such diversity has made exchanges and mutual learning among civilizations relevant and valuable.[...] Second, civilizations are equal, and such equality has made exchanges and mutual learning among civilizations possible [...] Third, civilizations are inclusive, and such inclusiveness has given exchanges and mutual learning among civilizations the needed drive to move forward $[\ldots]$ )

Both topicalisers and sequencers signal the schematic text structures and provide framing information about the discourse. The difference is that by using sequencers, the speech is organized in a linear way.

The statistics shows that there is greater use of topicalisers in American speeches than in Chinese speeches (49.6 vs. 9.9 token per 10,000 words). It means that new arguments or ideas are more commonly introduced in American texts than in Chinese ones. Meanwhile, sequencers have been found to be more frequent in Chinese speeches than in American speeches. (13.5 vs. 8 token per 10,000 words). Among the 30 speeches, almost $80 \%$ Chinese speakers use sequencers in their speeches, while only $27 \%$ American speakers use sequencers. The possible conclusion is that American speakers apply more topicalisers than Chinese speakers to provider the framing support for a better understanding, while Chinese speakers prefer more linear style to organize their speeches.

\subsubsection{Code Glosses}

Code glosses serve the function of supplying additional information by explaining, rephrasing or elaborating what has been said. When predicting certain information might be difficult and need explaination, the speakers explain them to ensure that details or significance of particular information can be understood. Making the listeners follow the speech easily needs to make the text logic and coherent, therefore, code glosses assist the realization of logical appeals.

In Example (9), the speaker calls on all nations to behave properly. Realizing that listeners need further explanation toward "acceptable international behavior", he use the code gloss "that means" to give more detailed explanation. Example (10) is a similar case in Chinese speech. The code 
gloss “相当于(That is equal to)” is used to elaborate what has been said. The speaker provides a more concret figure to show the reduction in carbon emission. As people tend to have a better understanding toward a concrete figure than an ambiguous percentage, the use of code glosses helps to make the text clearer and easier for listeners to understand.

(9) With regard to maritime disputes, it's critical that all nations have a clearly understanding of what constitutes acceptable international behavior. That means no intimidation, no coercion, no aggression, and a commitment from all parties to reduce the risk of mistake and miscalculation.

（10）２013 年与 2005 年相比, 中国碳排放强度下降 $28.5 \%$, 相当于少排放二氧化碳 25 亿吨。

(Compare 2013 with 2005, China's carbon emission decreases $28.5 \%$. That is equal to reduction in 2.5 billion tons of carbon dioxide emission.)

Code glosses are more frequent in English speeches than in Chinese speeches. (11.5 vs. 4.1 tokens per 10,000 words). American speakers seem to provide more clarification to the audiences. This can be explained by the diferent rhetorical style in different cultures. American discourses are more "reader-oriented", while Chinese discourses are more "“cauthor-oriented". The "reader-oriented" discourse usually calls for more clarification by authors, which would explain the different frequency of code glosses in the two sub-corpora.

When you're trying to persuade, the chances of your success depend a lot on whether your arguments make sense, or are logical. All the meta-discourses mentioned above, transitions, frame markers, and sequencers, contribute to the rational appeal of the discourse by guiding the audience in the discourse and making the contents easier to understand. To achieve the rational appeal, the overall use of transitions, frame markers, and code glosses is significantly greater in American texts than in Chinese texts. The only sub-category of discourse markers that are used more frequently by Chinese speakers is sequencers. As the persuasive strategy used in the speech is usually decided by speakers' judgement toward audience's expectation, we may say that in American culture, there is a higher preference toward explicit expression of logical relationship between the arguments, or it is the author's duty to make everything clear to the audience. However, the decoding of logical relationship of arguments falls more upon audiences in Chinese discourse. Besides, there is a preference for the sequential, step-by-step arrangement of information in the Chinese speeches.

\subsection{Meta-discourses Contributing to Credible Appeal}

Apart from rational appeals, credible appeals or ethos is another important factor that influences the realization of persuasion function. If the writer can present to the reader an honest, trustworthy, authoritative and competent personage, the reader is more likely to be persuaded. It is found that items that contribute to the realization of ethos include boosters, hedges, self-mentions and evidentials. The statistics show that there is no significant difference between the boosters, evidentials, and self-mentions, but there is a higher frequency of hedges and self-mentions in the American sub-corpus than the Chinese sub-corpus. The statistics also reveal that English speeches actually use more hedges than boosters to achieve credible appeal, while Chinese speeches use more boosters than hedges.

Table 6. Meta-discourses contributing to credible appeal.

\begin{tabular}{lllll}
\hline & American sub-corpus & & Chinese sub-corpus & \\
\hline & Raw number & Per 1,000 words & Raw number & Per 10,000 words \\
\hline Boosters & 559 & 99.3 & 529 & 77.9 \\
Hedges & 994 & 176.6 & 50 & 7.4 \\
Self-mentions & 2442 & 433.8 & 827 & 0.227 \\
Evidentials & 35 & 6.2 & 52 & 0 \\
Total & 4030 & 715.9 & 1458 & 7.7 \\
\hline
\end{tabular}

\subsubsection{Boosters}

Boosters function to convey the writer's certainty and assurance in the arguments and emphasize what is being discussed. In political speeches, although the speakers are usually celebrities, they still need to re-establish credibility in the discourse. Let's look at the following examples.

(11) There's no question in our view that every nation must protect its citizens against crime and attacks online, as well as off. But we must do it in a manner that's consistent with our shared values.

(12) “天高任鸟飞，海阔凭鱼跃。”我始终认为，宽广的 太平洋有足够的空间容纳中美两个大国。中美双方应该加 强对话, 增信释疑, 促进合作, 确保中美关系始终不偏离 构建新型大国关系的轨道。

("The sky is unlimited for birds to fly at ease, as the ocean is boundless for fish to leap at will." I have always believed that the vast Pacific Ocean has ample space to accommodate our two great nations. China and the United States need to step up dialogue, enhance trust, dispel misgivings, and advance cooperation, so as to make sure that our relations stay firm on the track toward a new model of major-country relationship.)

In example (11), the speaker uses boosters like "there is no question" and "must" to express his certainty on the issue of protecting American citizens against crime and attack. He also uses "must" to express an assertive attitude that the manner should be consistent with the shared values. Adopting an assured attitude toward something with common agreement, the speaker builds up a positive image and wins the support of his audience. Example (12) also apply “应该” (should) “确保” (make sure) and “始终” (always) to emphasize the speaker's attitude toward Sino-American 
relationship. The boosters help to convince the audience that Chinese government will be friendly and cooperative and boost up audience's confidence toward Chinese government's policy. In both examples, speaker establishes a confident image and builds solidarity between speaker and audience by making full commitment to the arguments, and credible appeal is achieved during this process.

As can be seen in Table 6, this is the category heavily used in both American and Chinese speeches (99.3 vs. 77.9 tokens per 10,000 words). No statistically significant differences have been found in the frequency of boosters between the two sub-corpora. Boosters can display strong commitment in the statement and establish a confident image of speaker, which are important in both American and Chinese culture.

\subsubsection{Hedges}

Opposite to boosters, hedges imply a statement that is based on the writer's plausible reasoning rather than certain knowledge. In public speaking, the acceptance or rejection of an argument greatly depends on readers' evaluation of the credibility of the speakers and the information he conveys. By showing uncertainty of his claim, the speaker builds up a cautious, humble and considerate image, which helps to achieve credible appeal of the discourse.

As can be seen in Table 6, hedges in the English speeches are used much more than in Chinese speeches. (176 vs. 7.4 tokens per 10,000 words) It is indeed one of the categories that the English and Chinese sub-corpora present the greatest frequency difference. This result suggests that hedges are used in much less in Chinese speeches than in English speeches. Besides that, the purpose of using hedges also seems to be different. The most frequently used hedges in American corpus are modal verb hedges like would and could, while the most frequently used hedges in Chinese corpus are adverbial and adjective hedges like 基本(basic) and 一定(certain).

Let's look at the following sentences:

(13) And I will say again, we would not have gotten to this point and I think our colleagues in Iraq would acknowledge were it not for their staff, whose work is often done under trying conditions - and I might add, Mr. Secretary, I think their work remains as important as it ever has been.

(14) 目前, 中国除了大豆有一定缺口、需要进口弥补以 外，小麦、稻谷、玉米三大品种产需都实现了基本平衡。 (At present, aside from the soy bean which needs imports to fill the supply gap, China enjoys a basic balance in the production and demand of the three staple grains of wheat, rice and corn. China has an adequate grain reserve and sufficient market supply.)

In example (13), "I think" is used to show respect to the audiences by emphasizing that those are only speakers' personal viewpoints and the audience may have different opinions. "would" and "might" are also used to make the statement less direct. Example (14) limits the scope of the insufficiency, preventing the addressees from amplifying the influence of the insufficiency, and closing down the possibility of causing unnecessary upset with the hedge“一定” (certain). The other hedge “基本”(basic) helps to avoid the absoluteness, thus it makes the utterance more objective and reliable. The above typical examples show that hedges are usually used in American speeches to show respect to the audience by avoiding directness and opening the possible negation, while in the Chinese context, the hedges, by adjusting the degree of certainty, usually aims to eliminate negative suspicion by making the statements more objective and reliable.

In short, hedges are used much more frequently in American than in Chinese political speeches. American speakers use hedges to emphasize the subjectivity of speakers' opinion, while Chinese speakers use hedges to avoid the absoluteness. To achieve credibility, Chinese politicians, as representatives of the government, tend to build a confident and authoritative image. As for American politicians, the credible image is more likely to be achieved by weakening compel and expressing respect to their audiences.

\subsubsection{Self-Mentions}

Self mentions indicate the degree of explicit author presence in the text and also play an important role in the realization of credible appeal. When combining with boosters and hedges and attitude markers, self mentions emphasize the speakers' personal responsibility for the arguments. Although the American speakers seem to apply more self-mentions in general, the statistic shows significant difference between the two sub-corpora (Table 6).

Self mentions can be further split into singular and plural form. The singular form is associated with the degree of explicit presence of the speaker in the speech, including first-person pronouns like $I, m y$, and mine, while the plural form is an indicator of the government or institution the speaker represent, like we, our, ours or China, America. In a speech, the speaker might change his own status between $I$ and we.

Table 7. Plural and Singular form of Self-mentions.

\begin{tabular}{lllll}
\hline & American sub-corpus & & Chinese sub-corpus \\
\hline & Raw number & Percentage & Raw number & Percentage \\
\hline Plural form & 1689 & 70.10 & 773 & 93.50 \\
Singular form & 722 & 29.90 & 54 & 6.50 \\
Total & 2411 & 100 & 827 & 100.00 \\
\hline
\end{tabular}

As we can see from Table 7, both American speakers and Chinese speakers use more plural form of self-mentions than the singular form, which means that in both cultures the speakers turn to his public status more frequently than his personal status in political speeches. In Chinese political speeches, only $6.5 \%$ of all the self-mentions are in singular 
form, which might indicate that Chinese speakers tend to avoid singular form of self-mentions in political speeches.

Let's look at the examples to see how these two types of self-mentions attributing to a credible image.

(15) I love Australia - I really do. The only problem with Australia is every time I come here I've got to sit in conference rooms and talk to politicians instead of go to the beach.

(16) 中方建议, 推动亚信成为覆盖全亚洲的安全对话合 作平台, 并在此基础上探讨建立地区安全合作新架构。中 方认为, 可以考虑根据形势发展需要, 适当增加亚信外长 会乃至峰会频率，以加强对亚信的政治引领、规划好亚信 发展蓝图。

(China proposes that we make CICA a security dialogue and cooperation platform that cover the whole of Asia and on that basis explore the establishment of a regional security cooperation architecture. China believes that it is advisable to increase the frequency of CICA Foreign Ministers meetings and even possibly summits in light of changes of the situation so as to strengthen the political guidance of CICA and chart a blueprint for its development.)

In example (15), the frequent use of "I" shows the writers' love toward Australia as an ordinary man rather than a politician, thus building up a sincere, honest and trustworthy personage to close the relationship between the speaker and the audience. In this way, the audience is more likely to accept his following argument.

In Chinese political speeches, however, singular self-mentions are rarely used. They are only used at the very beginning of speeches in a fixed pattern to identify the speaker and show welcome to audiences. The more typical application of self-mentions is the use of we or the mention of one's country like example (16). The use of “中方” (China) clearly indicates that the speaker is only the representative of the Chinese government. The proposal put forward here is out of an institution rather than the speaker's own will, which make the statement more serious and formal.

Self-mentions can contribute to credible appeal. Plural self-mentions, being the representatives of government or institution, make the statement more formal, while singular self-mentions help to shorten the psychological distance between speaker and audience. Both American and Chinese speeches apply self-mentions to build up the speaker's image, the difference is in the use of singular self-mentions. Singular self-mentions are rarely used in the Chinese sub-corpus, probably because that the Chinese conception of credibility needs a more formal and authoritative image in political discourse. Comparatively speaking, in the American political discourse, singular self-mentions are used more frequently because a personal image is needed to build up speaker's personage and make his statement more credible.

\subsubsection{Evidentials}

Evidentials are indicators of the source of information and they distinguish who is responsible for a positin and while this may contribute to a persuasive goal. They establish intertextuality, thus helping speakers to persuade listening by associating their message with something they have alrdady trusted. In political speeches, speakers use evidentials to improve their credibility by drawing on external sources to support their own views.

Evidentials are among the least common meta-discourse features in the both sub-corpora. We didn't find significant statistic difference between the American sub-corpus and the Chinese sub-corpus (see Table 6).

Table 8. Sources of quotation.

\begin{tabular}{lllll}
\hline & American sub-corpus & & Chinese sub-corpus \\
\hline & Raw number & Percentage & Raw number & Percentage \\
\hline Celebrity in history / Classical works & 4 & 12.5 & 38 & 73.1 \\
Celebrity of the time/ Official statistics & 22 & 68.8 & 12 & 23.1 \\
Ordinary people & 6 & 18.8 & 2 & 3.8 \\
\hline
\end{tabular}

But we do find some difference in the source of the quotation. We classified the source of evidentials into three groups: celebrity in history/classical works in history, celebrity of the time, and ordinary people. Table 8 shows that, American speakers quoted most from celebrity of the time or official statistics (68.8\%), while Chinese speakers quoted most from ancient poems or proverbs containing traditional Chinese values (73.1\%).

Example 17 is from Obama's talk on immigration issues. In his speech, Obama quoted from President Bush to indicate that even his predecessor had similar views like his, thus persuaded the audience to believe in what he said. The Chinese speakers also use evidentials to refer to the information sources and build up the credibility of the statements, but they are more likely to quote from celebrity in history or classical works, which seem to be more authoritative and reliable in Chinese culture. In Example 18, the speaker quoted from an ancient Chinese saying, an American poem, and the ancient Chinese philospher Laozi to express the view that building new model of Sino-American relationship is not easy. It will take a long time and a lot of efforts. Instead of defending an argument or winning support for a statement, evidentials here are used more for rhetorical effects, making the contents and the speaker sound more authoritative by referring to the proven authority in ancient times. The American speakers sometimes quote from people who are not so famous to the public, like their family members (18.3\%), while Chinese politician rarely use evidentials in this way $(3.8 \%)$.

(17) As my predecessor, President Bush, once put it: "They are a part of American life."

(18) 中国有句谚语: “只要功夫深，铁杵磨成针。”美 国诗人摩尔说: “胜利不会向我走来，我必须自己走向胜 利。”构建中美新型大国关系是一种使命和责任。“合抱之 
木，生于毫末；九层之台，起于累土。让我们用积土成山 的精神, 一步一个脚印, 携手推进新型大国关系建设, 努 力开创中美关系更加美好的明天! (As a Chinese saying goes, "Constant grinding turns an iron rod into a needle." The American poet Marrianne Moor also said, "Victory won't come to me unless I go to it." It is our mission and responsibility to build a new model of major-country relationship. "A huge tree that fills one's arms grows from a tiny seedling; a nine-storied tower rises from a heap of earth." Let us demonstrate such hard work and perserverance. Take solid steps as we move forward, and work together to build a new model of major-country relationship between China and the United States and create an even brighter future of China-US relations.)

The difference in achieving credible appeal through evidentials might be caused by the cultural need for political speeches. Speakers of the political speeches are usually celebrity with high social status. When the American speakers seek for external support to their argument, those quotations from their peers or ordinary people can help to convince the audience or shorten the psychological distance between the speaker and the audiences. Chinese quotations from the ancient poems or proverbs are an authoritative support as well as a proof of the knowledge and personal quality of the speaker.

\subsection{Meta-discourses Contributing to Affective Appeal}

An emotional appeal is a method of persuasion that's designed to create an emotional response. In public speaking, speakers may use engagement markers and attitude markers to earn emotional support from the audience and thus achieve the persuasive function.

Table 9. Meta-discourses contributing to affective appeal.

\begin{tabular}{|c|c|c|c|c|c|}
\hline & \multicolumn{2}{|c|}{ American sub-corpus } & \multicolumn{3}{|c|}{ Chinese sub-corpus } \\
\hline & Raw number & Per 1,000 words & Raw number & Per 10,000 words & T-test \\
\hline Engagement Markers & 2499 & 443.9 & 1540 & 226.8 & .001 \\
\hline Attitude Markers & 582 & 103.4 & 442 & 65.1 & .000 \\
\hline Total & 3081 & 547.3 & 2134 & 291.9 & .000 \\
\hline
\end{tabular}

\subsubsection{Engagement Markers}

Engagement markers are those devices that explicit the readers' presence to involve readers into the discourse. In a speech, whether the speaker can involve his audiences or not will greatly influence the persuasiveness of his speech. Through the use of engagement markers, speaker can bring himself together with their audience as members pursing similar goals, thus gaining emotional support and achieving the affective appeal in his speech. The number of engagement markers have been found to be higher in the sub-corpus in English than in the Chinese one (443.9 vs. 226.8 per 10,000 words), which means generally the American speakers are more inclined to engage their audiences through this meta-discourse device.

Engagement markers include personal pronouns, questions and directives. Let's look at the following examples.

(19) Every day, we should ask ourselves three questions as a nation: How do we attract more jobs to our shores? How do we equip our people with the skills they need to get those jobs? And how do we make sure that hard work leads to a decent living?

(20) 女士们、先生们、朋友们! 中国人民正在努力实现 中华民族伟大复兴的中国梦，同各方一道努力实现持久和 平、共同发展的亚洲梦, 为促进人类和平与发展的崇高事 业作出新的更大的贡献!

(Ladies and gentlemen, dear friends, the Chinese people in their pursuit of the Chinese dream of great national renewal will stand ready to support and help people in Asia to realize their own dreams. Let us work together for realizing the Asian dream of lasting peace and common development and make greater contributions to advancing the noble cause of peace and development of the mankind.)
Personal pronouns in public speeches refer to inclusive we (our, us) and the second person pronoun you (your) with the reader. In example (19), "we", "our", and "ourselves" are used to imply that the existing problems are common problems that the audiences need to face, creating solidarity with the audiences. In example (20), “女士们”、“先生们”、 “朋友们” are used to draw readers' attention and include them into the text as participant. In both American and Chinese speeches, such involvement can lead to emotional support of the audiences since people intend to be more concerned about something closely related to them.

Questions are also used as a device to draw the reader's attention and involve the audience to explore the issue. In example (19), the three questions lead the audiences to consider those problems put forward by the speaker. Question marks appear 54 times in the American sub-corpus but it doesn't show up in the Chinese sub-corpus, which means question is not a prefered linguistic device in Chinese political speeches.

Another form of engagement markers is directives which instruct the audience to perform an action or to see things in a way set by the speaker, including imperatives (consider, imagine), modals of obligation (must, should) and predicative adjectives expressing judgments of necessity or importance. In political speeches, more often than not, directives occur near the end of speeches where the writer motivates the audience to take actions. In example (20), the Chinese expression “同各方一道努力实现持久和平、共同 发展的亚洲梦” (Let us work together for realizing the Asian dream of lasting peace) calls on audience to perform something suggested by the speaker, aligning desires of the speaker with those of audience. Chinese speakers apply this meta-discourse device more frequently than their American 
counterpart.

Generally speaking, American politician use more engagement markers than the Chinese counterpart. But American politician tend to use more questions while Chinese politician tend to use more directives.

\subsubsection{Attitude Markers}

Attitude markers indicate the writer's affective attitude to arguments which convey surprise, agreement, importance, obligation, frustration and so on. The attitude markers are used to express speakers' own opinion which is based on the speaker's assumption of the shared attitudes, values and reactions. And through this method, the speaker can suck the audiences into a conspiracy of agreement.

A higher number of attitude markers is found in American sub-corpus than in the Chinese sub-corpus (103.4 vs. 65.1 per 10,000 words), which means American speakers more frequently involve their personal feeling into the argument.

(21) And I was -- it's terrible being dated. I was -- I did speak the first year that the Center for American Progress was inaugurated, and here I'm speaking at the 10th anniversary. And the amazing thing is they're still going; that's having me speak there first.

(22) 我们希望美方始终恪守中美三个联合公报精神，坚 持一个中国政策，以实际行动反对“台独”，支持两岸关系 和平发展。我们也希望美方切实履行承认西藏是中国一部 分、反对“西藏独立”的承诺, 慎重妥善处理涉藏问题。

(We hope that the United States will adhere to the three Sino-US Joint Communiques and the one China policy, oppose "Taiwan independence" and support the peaceful development of relations across the Taiwan Straits with concrete actions. We hope that the United States will truly honor its commitment of recognizing Tibet as part of China and opposing "Tibet independence", and will handle Tibet-related issues in a prudent and proper manner.

The attitude markers in example (21) overtly disclose the speakers' personal likes and dislikes, and build up rapport with the audiences by making the audience share how the speaker feel. Chinese politician seldom express their personal feeling overtly to influence the audience in public speaking. Emotions are expressed in a more indirect manner. Let's look at example (22). By using two attitude markers “希望”(hope), the speaker's attitude is infused into his expectation, relieving psychological pressures on the audiences and made the latter feel that their future actions are of great importance for the realization of such expectations. In short, American speakers use attitude markers more directly while Chinese speakers prefer to express their attitude in a less direct way in the realization of affective appeal.

To achieve affective appeal, the American speakers still use more meta-discourse markers than their Chinese counterpart statistically. But the text analysis reveals a different cultural style to achieve affective appeal. American speakers leave more room for different opinions in the engagement process and express personal feeling in public speeches more frequently.

\section{Discussion}

The quantitative analyses reported in the previous section have revealed that American speakers tend to use more meta-discourse markers than their Chinese peers to achieve logical, credible and affective appeal. This result is in line with previous cross-cultural studies [12], [14], [18]. This result, to some extent, is due to the different constructional characteristics of Chinese and English. Chinese is parataxis language which requires less or no connectives to construct a discourse. Besides, subjects are not obligatory in Chinese sentences, therefore, the frequency of pronominal subject like "we" is also much less used in a Chinese discourse. The difference in grammatical rules of these two languages actually leads to the statistic difference in the frequency of transition markers, self-mentions, and engagement markers. At the same time, the higher frequency of meta-discourse markers of the American speeches is also conditioned by the broad socio-cultural context.

Since these meta-discourse markers are explicit signals of ideas in a speech, the fewer number of these markers will make the relationship of information less explicit. In the discourse with less explicit guidance, listeners need to spare more efforts to figure out the relationship of the information and ideas. Following Hinds' [19] distinction between writer and reader relationship, it seems that American speeches favors a speaker-responsible style while Chinese speakers favors a listener-responsible style in the interpretation of information. In the Chinese culture, authority is not expected to be responsible for explaining. However, American speakers more commonly make explicit the logical relationship between his ideas to ensure the meaning can be interpreted as intended.

Another finding of this research is that American speakers use the most meta-disicourse markers to achieve ethos, followed by pathos and logos, while Chinese speakers use the most meta-discourse markers to achieve pathos, followed by ethos and logos. This finding shows that comparatively speaking, Chinese rhetorical norms tend to encourage the framing of ideas "rely less on formal logic and more on experiential knowledge in reasoning". [20]

To achieve logical appeal, English speeches apply more meta-discourse markers (logical maker, topiclisters, and code glosses) in the context than Chinese speeches to construct the discourse and guide the listeners. The only meta-discourse that occurs more frequently is sequencers, which means that Chinese speaker, when giving guidance in their discourse, have a higher tendency to choose a sequential order for explaining his argument than the American counterpart. The sequencers, used for step by step explanation, require less interactive effort than the other framing markers. When the Chinese speaker adopts sequencers to construct his discourse, he is actually expecting the audience to accept and follow his argument step by step. Meanwhile, that there is actually a higher expectation of speaker-listener interaction in the American speech, which might explain the lower frequency in the use of sequencers by the American speakers. 
Meta-discourses are applied in both American and Chinese corpura to achieve credible appeal. Boosters are used to express speakers' certainty, while hedges try to avoid certainty. The balance of hedges and boosters in a text thus indicate the extent of speakers' tolerence toward alternatives in what he says. English speeches use more hedges than boosters, while Chinese speeches use more boosters than hedges. A significant higher frequency of hedges in American speeches and different preference for the use of hedges has also been found. This can be explained by the cultural practice prevailing in America and China. Hedges are self-reflective linguistic expression emloyed to express epistemc modality and modify the illocutionary force of speech acts. [21-22] American politicians, usually chosen through voting, tends to build up a modest and considerate profile by acknowledging alternative viewpoints, while their Chinese counterparts are less compelled to hedge their positions but more likely to preceive a need to express certainty and build up authority. Similar cultural influence can also be found in the use of evidentials. When turning to external support of arguments, Chinese speakers tend to turn to the classical works in history to build up an authoritative image. It is also found that singular self-mentions are used more frequently in American sub-corpura than in Chinese sub-corpura, which might indicate that a personal image is not the preferred way to establish credibility in Chinese speeches. As we all know, American culture values individualism while Chinese culture values collectivism. Chinese culture does not encourage too much explicit of oneself in a political discourse. Instead, Chinese politicians more frequently mention the country or government they represent. In American speeches, the speaker is more likely to express his own feeling to build up personal personage. Similar cultural impact can also be found in the use of evidentials. Chinese speakers are more likely to quote from ancient poems or proverbs to build up an authoritative image, while American speakers are more likely to quote from peers or ordinary people to build up a modest image to win support from the audiences. To sum up, meta-discourses (hedges, boosters, self-mentions, and evidentials) are used in both American and Chinese political speeches to build up a credible image of the speaker, but the concept of a credible image is different in these two cultures. In American culture, the audience expects a confident speaker, but they also expect the speaker to build up a personal persona in his speech, while Chinese audience is more likely to expect an authoritative image in political speech.

To achieve affective appeal, both American and Chinese political speeches try to evoke pathetic agreement of the audience, but American speakers make greater use of both engagement marker and attitude marker. The higher frequency of engagement markers in American speeches signals more consideration and respect for the audiences, which is in line with our previous finding that American discourses are usually more speaker-responsible. It is also found that American speakers more frequently use attitude markers to express their own attitude and assumption of the sacred attitudes, values and reactions to information.

\section{Conclusion}

This study has tried to describe how meta-discourse helps to achieve persuasion in American and Chinese speeches and revealed the difference in the use of meta-discourse markers and cultural factors that influences the difference. First, the study suggests a great influence of meta-discourses on the persuasiveness of political speeches. Second, American speakers generally use much more meta-discourse markers in the realization of logical appeal, credible appeal, and affective appeal. Third, the American speeches use more hedges than booster to build up credibility, while Chinese speeches use more boosters than hedges on the contrary. A significant higher frequency of hedges in American speeches and different preference for the use of hedges has also been found. Fourth, to achieve affective appeal, American speakers make greater use of engagement markers and attitude markers. These salient differences have been contributed to the grammatical difference of languages and the culturally preferred rhetorical strategies.

This study has provided a descriptive and empirical study of persuasive function of metadiscourse in a single domain. Meanwhile, to develop a more comprehensive understanding of metadiscourse markers in terms of persuasion requires comparable data from different disciplines. Besides, the results need to be confirmed on a larger corpus. Such finding can help public speakers build up knowledge about cross-cultural communication and adjust their persuasive strategies according to the expectation of the audience in the new cultural context.

\section{Acknowledgements}

This research was supported by the Education Department Foundation of Guangxi Zhuang Autonomous Region through Grant LX2014028, and the Philosophy and Social Science Foundation of Guangxi Zhuang Autonomous Region through Grant 15FYY001.

\section{Appendix: Meta-discourse Features in the English and Chinese Sub-corpus}

\section{Transition Markers}

Additive: and, in additionally, likewise, also, moreover, and, furthermore; addition, similarly; Contrasive: however, but, yet, rather, instead, though, otherwise; instead of, no matter; Consecutive: thus, therefore, then, as a result, so, so that because, as a consequence

Additive: 而且, 并且, 同时, 还, 也, 并, 此外, 不 但......而且....... 不仅 ......而且....... 或且; Contrastive: 但，但是，相反，反之，却，而不是，否则; Consecutive: 因此, 所以,从而, 因为, 由于, 为此

\section{Frame Markers}

Sequencer: first, first of all, firstly, second, secondly, third, 
thirdly, next, to begin, next, finally; Topicalisers: at this point, now, to conclude, to repeat, to summarize, today, with regard to, in terms of, in light of, in short, aim, desire to, focus, goal, intend to, would like to, want to, back to, move on, now, return to, turn to, well, bring to, so

Sequencer: 一是，二是，三是，第一，第二，第三，首 先, 其次, 最后; Topicalisers: 在这里, 这里, 在此, 今天, 在以下.....方面, 关注点有..., 提出几点倡议, 目的就是

\section{Code Glosses}

that is, that means, this means, which means, in other words, namely, known as, in fact. e.g. such as, for example, for instance, give an example

\section{意为, 就是, 即(即为), 具体说来}

\section{Evidentials}

“", cite, quote, according to, cited 好

“”, 说, 说过, 据, 根据, 有句, 指出, 正所谓, 说的

\section{Boosters}

reveal, highlight, confirm, emphasize, conclude, hold, particularly, highly, strongly, actually, especially, entirely, essentially, critical, obvious, wise, importance, contribution, value, worth, dangerous, great

相信, 显示, 发现, 知道, 证明, 表明, 极大, 强调, 确保, 更, 更加, 重申, 确保, 必须, 必然, 肯定, 一定, 理应, 应该, 坚定不移, 都, 将, 事实上, 总是, 当然, 从不, 绝不, 从未, 真正, 实在, 当然, 都, 决不,

\section{Hedges}

about, almost, appear, argue, around, broadly, certain, claim, could, doubt, essentially, estimate, fairly, feel, generally, in general, might, mostly, often, ought, perhaps, possible, possibly, nearly, probably, quite, should, rather, relatively, seems, sometimes, suggest, tend to, uncertain, usually, would

可能, 一定(表示限定), 多数, 经常, 往往, 大体, 总 体, 很, 相对, 有时, 有些,

\section{Self Mentions}

I, me, my, mine, our, us, we, America, the United States, our countries

我, 我们, 我国, 中方, 作为...

\section{Attitude Markers}

!, agrees, amazing, appropriate, disappointed, dramatically, even X, important, inappropriate, prefer, preferable, remarkable, unique, valuable, best, better, good, reasonable,

!, 同意, 反对, 期待, 希望, 愿, 正确, 重要, 重大, 必要, 首要, 有望, 往往, 甚至, 重要的是, 最好

\section{Engagement Markers}

?; Personal pronoun: we (inclusive), us (inclusive), our (inclusive) you, your, folk, everybody; Directives: let's, look, imagine, must, need to, have to, need to, ought, together

?; Personal pronoun: 我们, 你, 你们, 两国, 各国, 双 方, 女士们, 朋友们, 先生们; Directives: 让, 必须, 需要, 要, 不要, 共同, 携手, 共同

\section{References}

[1] Hyland, K., 2005. Metadiscourse. Continuum, London. 14-15.
[2] Crismore, A., \& Farnsworth, R., 1989. Darwin and his readers: Exploring interpersonal metadiscourse as a dimension of ethos. Rhetoric Review, 8 (1), 91-112.

[3] Vande K., William J., 1985. Some exploratory discourse on metadiscourse. College Composition and Communication 36, 63-94.

[4] Hyland, K., 1998. Persuasion and context: The pragmatics of academic metadiscourse. Journal of pragmatics, 30 (4), 437-455.

[5] Halliday, M. A., 1994. Functional grammar. London: Edward Arnold.

[6] Hyland, K., Tse, Polly, 2004. Metadiscourse in academic writing: a reappraisal. Applied Linguistics 25 (2), 156-177.

[7] Hyland, K., 2000. Hedges, boosters and lexical invisibility: Noticing modifiers in academic texts. Language Awareness, 9 (4), 179-197.

[8] Bunton, D., 1999. The use of higher level metatext in Ph. D theses. English for Specific Purposes, 18, S41-S56.

[9] Hyland, K., 1996. Writing without conviction? Hedging in science research articles. Applied linguistics, 17 (4), 433-454.

[10] Crismore A, Markkanen R, Steffensen M S. 1993, Metadiscourse in persuasive writing a study of texts written by American and Finnish university students. Written communication, 10 (1): 39-71.

[11] Hyland, K., 2002. Authority and invisibility: Authorial identity in academic writing. Journal of pragmatics, 34 (8), 1091-1112.

[12] Mauranen, A., 1993. Contrastive ESP rhetoric: Metatext in Finnish-English economics texts. English for specific Purposes, 12 (1), 3-22.

[13] Neff-van Aertselaer, J., \& Dafouz-Milne, E., 2008. Argumentation patterns in different languages: An analysis of metadiscourse markers in English and Spanish texts. Developing contrastive pragmatics interlanguage and cross-cultural perspectives, 87-102.

[14] Dafouz-Milne, E., 2008. The pragmatic role of textual and interpersonal metadiscourse markers in the construction and attainment of persuasion: A cross-linguistic study of newspaper discourse. Journal of pragmatics, 40 (1), 95-113.

[15] Mur-Dueñas, P., 2011. An intercultural analysis of metadiscourse features in research articles written in English and in Spanish. Journal of pragmatics, 43 (12), 3068-3079.

[16] Hu, G., \& Cao, F., 2011. Hedging and boosting in abstracts of applied linguistics articles: A comparative study of English-and Chinese-medium journals. Journal of pragmatics, 43 (11), 2795-2809.

[17] $\mathrm{Mu}, \mathrm{C} ., 2$ 2010. A Contrastive Analysis of Metadiscourse in Chinese and English Editorials. Foreign Language Learning Theory and Practice, 4, 006.

[18] Valero-Garcés, C., 1996. Contrastive ESP rhetoric: Metatext in Spanish-English economics texts. English for Specific Purposes, 15 (4), 279-294.

[19] Hinds, John, 1987. Reader versus writer responsibility: a new typology. In: Connor, U., Kaplan, Robert, B. (Eds.), Writing across Languages: Analyses of L2 Texts. Addison-Wesley, Reading, pp. 141-152. 
[20] Nisbett, R. E., Peng, K., Choi, I., \& Norenzayan, A., 2001. Culture and systems of thought: holistic versus analytic cognition. Psychological review, 108 (2), 291.

[21] Holmes, J., 1982. Expressing doubt and certainty in English. RELC journal, 13 (2), 9-28.
[22] Holmes, J., 1988. Doubt and certainty in ESL textbooks. Applied linguistics, 9 (1), 21-44. 